\title{
1. An alternative ecological theory of the firm and its environment
}

To understand the behaviour of an organization you must understand the context of that behaviour - that is, the ecology of the organization. (Pfeffer and Salancik, 1978: 1)

The central thesis of this book is that we need an alternative ecological approach to studying the firm to fully appreciate the relations between any individual firm and its operational environment. This approach must accurately account for all resource flows back and forward between firms and their operational environment, centre on the degree to which an individual firm's operations scale the environment, must generalize at a level that accommodates idiosyncratic noise often ignored from the spatiotemporal context of individual firms, and must focus on the unique feature-factor relationship of any given firm and its environment. In short, an approach is required that aims to explain the adaptive responses of individual firms from the perspective of their interactions with regards to the distinctive operational environment they experience. The development of the ideas here draws heavily upon the works of Walter and Hengeveld (2014), Walter (2008), Hengeveld and Walter (1999) and many other related works associated with the on-going renaissance of autecology in the mainstream ecology literature (Rohde, 2005; 2013), works that ultimately seek to bring to life the pioneering works of Daubenmire (1947) and Andrewartha and Birch (1954; 1984) within which the individual entity is the interactive unit. None of these works have been written with the study of firms in mind and, therefore, it is through our interpretation of how autecology is developed elsewhere that guides the development of this book. That said; we believe this work to be the first time a recognized ecologist has contributed directly to theory and method development in the domain of organizational studies.

There are many theories of the firm, and all serve a particular purpose. Alvarez (2003: 260) argues that at present most theories of the firm are diverse and have been 'developed to address a particular set of characteristics and behaviours of interest' to the different sub-domains of organizational 
research. Further, she expresses a concern as to the type of firm to which such theories typically relate, that is, the traditional asset-intensive firm. This chapter seeks to sow the seeds of a new theory of the firm that is applicable to all firms, large or small, physical or virtual, private or public, knowledge or asset intensive and/or deemed to be entrepreneurial or non-entrepreneurial. This chapter seeks to position the proposed autecological theory of the firm and its environment relative to existing theories of the firm. In doing so, this chapter explains the expected contribution this alternative approach can make through the adoption of a different set of ecological assumptions regarding the interaction between individual firms and their unique operational environments. It will not be the aim of the chapter to critique the merits of other theories of the firm, but rather, to explain the nature of their underlying assumptions vis-à-vis those being advanced here from an autecological perspective.

To establish a clear distinction initially between the alternative autecological approach and what is currently accepted as organizational ecology (Hannan and Freeman, 1977; 1989), we can initially consider the contrast illustrated in Table 1.1. Although, these differences will be explained in greater detail throughout the book, this preliminary discussion seeks to establish within the reader's mind the essential underlying differences of the autecological approach. Non-controversially both approaches accept the existence in society of firms as social entities identifiable as having goals, boundaries and activities systems as outlined by Aldrich (1999).

However, that is the only similarity the two approaches share. In OE, firms are assigned membership to specific populations and/or communities that are deemed to experience a common environment. These are the primary conditions upon which the process of competitive selection is expected to optimize the fitness of surviving firms. Alternatively, firm autecology (hereinafter referred to as FA) does not rely upon arbitrary human abstractions (Reiners and Lockwood, 2010; Martinez and Aldrich, 2012) to construct boundaries so that individual firms can be provided membership of assumed populations and/or communities. Rather, selection processes that affect individual firms are assumed in the first instance to be related to the local events between any given firm and the operational environment, as Spomer (1973) envisages for individual organisms across the different circumstances they experience/create. The operational environment must always be first observed, rather than merely inferred. Following the lead of Mason and Langenheim (1957), we see the operational environment as being directed, timed, ordered and spaced by and across the lifeline of a given firm. 
Table 1.1 Alternative ecological assumptions

\begin{tabular}{|l|l|}
\hline \multicolumn{1}{|c|}{ Organizational Ecology } & \multicolumn{1}{|c|}{ Firm Autecology } \\
$\begin{array}{l}\text { 1. Firms exist ... } \\
\text { 2. Firms exist in populations sharing a } \\
\text { common environment ... }\end{array}$ & $\begin{array}{l}\text { 1. Firms exist ... } \\
\text { 2. Firms exist in proximity to other firms, } \\
\text { frequently sharing a common external } \\
\text { environment ... }\end{array}$ \\
$\begin{array}{l}\text { 3. Firms exist in populations sharing a } \\
\text { common environment that has limited } \\
\text { resources and therefore compete ... }\end{array}$ & $\begin{array}{l}\text { 3. Firms exist in proximity to other firms, } \\
\text { frequently sharing a common external } \\
\text { environment, but typically have their own } \\
\text { distinct operational environment ... }\end{array}$ \\
$\begin{array}{l}\text { 4. Firms exist in populations sharing a } \\
\text { common environment that has limited } \\
\text { resources and therefore compete and this } \\
\text { leads to the differential selection of } \\
\text { organizational forms with a better fit to } \\
\text { the environment. }\end{array}$ & $\begin{array}{l}\text { 4. Firms exist in proximity to other firms, } \\
\text { frequently sharing a common external } \\
\text { environment, but typically have their own } \\
\text { distinct operational environment } \\
\text { maintaining their existence through } \\
\text { solving problems in their operational } \\
\text { environment. }\end{array}$ \\
\hline
\end{tabular}

This conceptualization of the environment is quite radical in comparison to existing definitions of environment in organizational studies, and draws our explicit attention to specific environmental phenomena with which individual firms maintain operational relations. That is, those specific environmental factors, which any particular firm interacts with, and processes used in order to perform the resource exchanges necessary to maintain its existence.

While the existence of populations and/or communities is not denied, such aggregations should be viewed in the spirit of Hengeveld and Walter (1999), as ephemeral epiphenomena. That is, populations and/or communities are the transient by-product of individual-level behaviours and are in reality more conceptual than real. So while we may observe firms being situated in the same spatial or temporal zones, this does not mean that they experience a common environment through joint assigned membership. However, it is acknowledged that such structures may exist and indeed influence the process of selection experienced by any individual firm.

In $\mathrm{OE}$, competition is the central mechanism through which one organizational population supposedly 'reduces the hypervolume of environmental space in which another population can sustain itself' (Hannan and Carroll, 1992: 28-29). Viewed as ever-present, the process of competition is the foundation upon which niche theory (Hannan and Freeman, 1989) and its related concepts of density-dependence, legitimacy and carrying capacity have been developed. However, within the OE 
approach, competition is assumed to be difficult to observe directly and therefore indirect estimates of competition are developed from 'analyzing the densities of interacting populations'. Thus, the process of competition is reduced to mathematical modelling, rather than direct observation. In contrast, the FA approach views competition as only one of many potentially influential ecological processes that may influence firm survival, and it is not around which all investigation and organization is structured.

The FA approach requires that analysis does not reduce all other environmental factors down to a density-dependence explanation (see Andrewartha, 1984) and/or seek to focus upon pairs of interacting populations to formulate models based on competition. As such, assumptions about relatively homogeneous populations in relatively homogeneous environments are replaced by a concern for specific types of individual firms and the spatial-temporal variations present in their local conditions. There is no default assumption that particular traits held by firms predispose such firms to being able to better compete for resources and therefore achieve higher fitness vis-à-vis other comparable types of firms. Indeed, once we view individual firms as situated in highly variable environments, we can also entertain the idea of local adaptation detached from comparable measures of performance and therefore fitness (Nei, 2013). That is, we can imagine firms decreasing the degree of complexity within their activities in order to better match the requirements of their local environment. While firms may be located in proximity to other similar or dissimilar firms, what matters from the FA approach is the matching process between any particular firm and the operational environment it experiences and creates.

Finally, from the OE perspective, the individual firm is 'characterized by relative inertia in structure and in the other characteristics that define membership in a population' (Hannan and Freeman, 1989: 66). When too many firms enter a population relative to those that leave the population, the carrying capacity of the environment for that population is assumed to be exceeded, resulting in a process of intensification of competitive selection removing those firms with less fitness vis-à-vis other firms competing for available/scarce resources.

In contrast, the FA approach has already taken a different pathway to accounting for firm survival. Located in their unique operational environments as Spomer (1973) portrays organisms in an environmental setting, each firm is challenged by different circumstances and resource configurations; 'adaptive improvement is relative to the adaptive problem' encountered (Sahlins and Service, 1973: 15). From this perspective the most upwardly evolving and complex firms can exist alongside the simplest and seemingly static firms, each prospering in a common industry, rather than a common environment. 
Whereas OE seeks to understand the ecology of populations of firms (with the environment considered homogeneous), FA seeks to understand the local ecology of individual firms (within their local and operational environmental contexts). Such a difference in purpose extends beyond mere semantics. Whereas OE researchers see firms as being similar in principle and expected to conform to natural ecological laws, FA does not. From an FA perspective, the researcher is focused on understanding the nature of the interaction between individual firms and the environments they experience, create and/or modify. Consistent with the theoretical foundations of autecology, and to paraphrase Walter's (2013: 342) perspective on organisms, firms have industry-specific 'adaptations that mediate their interactions with the environment, and thus are the primary influences in what we call their ecology'. It would be expected that any industry could contain several subtypes of firms and therefore care must be exercised when generalizing even at the industry level. For example, previous research into the restaurant industry (Jones, 2009) has shown there are at least six distinct types of Pizza firms operating in unique ways. These different types of firms are observed to adapt to their operational environments in distinctly different ways.

Following the lead of Walter (2013: 351), the FA researcher should also rely upon 'heuristic generalizations that provide guidance on how to investigate the adaptations that underpin' firm-environment interaction. The focus is upon understanding the special ecological circumstances associated with firm adaptation. Further, such circumstances will be expected to align to the degree to which any individual firm scales its environment. To import ecological processes from beyond the scope of a particular individual firm's operating space increases the risk of developing pseudopredictions (Wiens, 1989). Essentially, an autecological approach seeks to avoid applying incorrect spatial and temporal scales to the study of local ecological processes.

In conclusion, this introductory section has sought to introduce the idea of FA, relative to the existing paradigm of OE (Hannan and Freeman, 1977; 1989). It is now appropriate to consider the development of ecological thought in the social sciences so that the current omission of autecology in the social sciences can be understood more clearly. The aim of this section is to illustrate how population/community level thinking has become so dominant in the study of firms. One other caveat worth noting is that the primary concern of FA is understanding ecological interactions within time and space, as they pertain to specific types of individual firms. Once such an understanding is achieved, further consideration can be also be given to accounting for evolutionary change across time and space. So FA is first and foremost an ecological approach, which can also potentially contribute to the eventual development of evolutionary explanations. 


\section{A SHORT INQUIRY INTO ECOLOGICAL THOUGHT}

Many have contributed to the development of ecological thought in the social sciences. However, as will be demonstrated, a process of premature convergence has largely led such thinking fundamentally down a set of closely related, and convergent pathways. While much progress has been made in developing and improving ecological models, many important ideas remain unseen, misunderstood and/or unexplored. This section aims to revisit, reorient and reexplain several ecological ideas and concepts, that while present during such thinking, have so far contributed little to our ecological investigation of individual firms in society. The specific focus of this discussion will be upon: 1) how we account for the interactions between firms, 2) the ability of firms to change their mode of operations, and 3) the capacity of firms to modify aspects of their operational environment. From an FA perspective, the past development of these three issues in OE has clearly proved to be intensely problematic.

To understand OE we must understand its intellectual roots. Whilst this inquiry into ecological thought will intentionally be short, and narrow in its focus, it will also not align neatly to the conventional history as documented elsewhere (Gibbs and Martin, 1959; Wallace, 1969; Young, 1974; Berry and Kassarda, 1977; Mlinar and Teune, 1978; Hawley, 1988; Hawley, 1998). Rather, it will retrace many important intellectual positions that were adopted and retained, and other ecological ideas that have yet to influence the domain of OE. The aim being to reveal the latent ecological foundations of an alternative ecological approach to the study of firms that have always been present, just not recognized, and therefore remaining undeveloped.

The OE paradigm gained most traction with the seminal work of Hannan and Freeman (1977), and this is commonly recognized. This work was significantly influenced by the proceeding work of Hawley (1944; 1950; 1968) and his work on human ecology. Hawley's work in turn drew upon the pioneering works of Park and Burgess (1921), McKenzie (1924; 1934a) and Park (1936). These initial works imported many ideas from plant and animal ecology (Young, 1974; Hawley, 1998) for use in sociological domains. It is therefore important to understand the nature of how certain ideas were imported, ignored, or eventually forgotten. Clearly, Hannan and Freeman's (1977) work did not appear from within a vacuum. The argument being made here is that a great deal of ecological consistency has remained within the sociological domain from the 1920s until present. Further, this consistency in thought has, as a natural consequence, worked against the appreciation that firms operate and interact within a heterogeneous environment, and thus against the development of an autecological approach to the study of firms in society. 


\section{Accounting for Interactions}

Of primary concern to any ecologist is accounting for the nature of interactions occurring between observed entities within a given environmental setting. If we accept that Park and Burgess (1921) represents one of the first major works in the field of sociological human ecology, then the initial ideas developed within this work are of great interest. They drew upon the ideas of many influential ecologists of the time, including Warming (1909), Wheeler (1910) and Clements (1916). Beyond drawing upon their natural sociological orientations to place the community at the centre of their research, Park and Burgess also adopted Warming's nonconforming definition of commensalism. As noted previously, an ecologically inconsistent interpretation of commensalism based on competitive relations was therefore introduced during the initiation of human ecology as a discipline. Commensalism was first defined by van Beneden (1869) and its ecological meaning as an interaction between two entities in which one benefits from the other, but the other is unaffected, and this has not altered across time and/or domains of enquiry as meaning anything other than that (see Dana, 1872; Clements, 1907; Alcock, 1911; Thomson, 1917; Borradaile, 1918; Flattely and Walton, 1922; Hegner, 1924; Pearse, 1926; Kudo, 1931; Allee, 1931; Odum, 1959; Reid, 1962; Pennak, 1964; Clarke, 1967; Rees, 1967; Martin, 1983; Blood and Studdert, 1988; Morris, 1992; Allaby, 2003; Rittner and McCabe, 2004).

The definition of Warming (1909), based on absolutely competitive relations, was offered without explanation, other than to say it is different from that which already existed. To further confuse matters, the Fuller and Conrad (1932) translation of Braun-Blanquet's (1928) classic work contains a translation error that reversed the ecologically consistent meaning attributed to commensalism by Braun-Blanquet. This incorrect translation of BraunBlanquet's (1928) work is of great importance, given the significant influence of Hawley's (1950) work on so many subsequent researchers in the organizational studies domain (see Hannan and Freeman, 1977; Pfeffer and Salancik, 1978; Astley, 1985; Carroll, 1985; Barnett and Carroll, 1987; Barnett and Amburgey, 1990; Barnett, 1994; Baum and Singh, 1994; Baum and Mezias, 1992; Aldrich, 1999; Greve, 2002; Rao, 2002). It would seem that human ecology; the intellectual forefather of $\mathrm{OE}$ was built upon the initial adoption of an incorrect interpretation of an important descriptor of ecological relations. Worse still, this inconsistent meaning was reinforced when Hawley (1950) adopted Fuller and Conrad's (1932) incorrectly translated meaning of commensalism. As a result, OE and other related evolutionary approaches (see Aldrich, 1979; 1999) have continued to use this central ecological concept in ways that preference the assumption of 
competitive relations over a range of other relations, mostly almost invariably non-harmful.

What remains a mystery is why Hawley (1950) adopted this over-reliance upon competitive relations that has to this day remained so influential in the formulation of OE. He clearly was very mindful of Kropotkin's (1902) idea of mutual aid and was mentored by Roderick McKenzie, whose writing on such matters was crystal clear. McKenzie's (1934b) collection of readings in human ecology provides a standard definition of commensalism, attributable to the work of prominent ecologist, Arthur Thomson (1914). It is somewhat ironic that Hawley (1944: 399) observed that 'the difficulties which beset human ecology may be traced to the isolation of the subject from the mainstream of ecological thought'. Whatever the reason, the adoption of a position relegating commensalism to be a descriptor for all manner of competitive relations (see Aldrich, 1999) has deprived OE researchers from accounting for all nine forms of coactions (see Haskell, 1949) in a manner that is ecologically consistent. It has ensured a strong emphasis remains upon competition as the primary organizing process of population/community relations. To be clear, and consistent with mainstream ecology, within the FA approach a commensalistic relationship connotes an interaction between two entities in which one benefits from the other, but the other is unaffected. In Chapter 2, the full range of coactions that an individual firm may experience will be discussed in detail. The next issue relates to the structural inertia attributed to firms in the OE approach, as contrasted to the idea of firm plasticity proposed in the FA approach.

\section{Firm Plasticity}

Many theories of the firm consider the ability of firms to adapt to changing environmental conditions a fundamental issue (Teece, Pisano and Shuen, 1997). While new ideas related to dynamic capabilities (Winter, 2003) emerge from scholars with many decades of thinking in this space, OE remains condemned as being too pessimistic (Dew, Goldfarb and Sarasvathy, 2006) vis-à-vis the ability of firms to remain agile and capable of out-running environmental change. That is, OE protagonists (Hannan and Freeman, 1984) see structural forces within firms providing at the start of their operations a selective advantage, but eventually then limiting these firms from being capable of transformative reorganization. While change is seen as possible to a firm's peripheral features, such change is not assumed to be easily achieved across core features of the firm. However, how one determines exactly what is core and what is peripheral from one firm to another remains a contested issue. As a result, OE is criticized strongly (Donaldson, 1995) for as yet not 
being able to adequately accommodate firm-level adaptive processes into this approach.

It is argued that such problems essentially are a consequence of Hannan and Freeman's desire to adopt a biological population ecology model within which the individual biological entities observed have very little scope to fundamentally change their morphological and/or physiological structures. Thus, it suits OE to insist that individual firms are limited in their ability to respond to environmental change, because that is how many ecologists (Elton, 1927; Hutchinson, 1957; Roughgarden, 1979), from whom they have adapted their ideas, essentially investigated the world. Strategic management theorists hold entirely different assumptions and argue that firms are often inspired to innovate and change their market positioning through innovative behaviours to overcome marketplace disruptions (Christensen, 2000).

FA offers a pragmatic solution to this on-going impasse that isolates $\mathrm{OE}$ from genuinely integrating various ideas from other theories of the firm, such as organizational learning. OE defends its structural inertia position from fully embracing organizational learning (Hannan, Polos and Carroll, 2007), suggesting that miscalculations due to opacity will restrict a firm's ability to reorganize firm features and align to changing environmental factors. However, if we reconceptualize what is the actual operational environment experienced by any given firm, we can recast the process of firm adaptation. We can place in front of the manager or entrepreneur an environment that is comprehendible; we can see through the assumed opaque context.

Think about the independent firms that have survived in your local neighborhood, despite the ever-increasing reach of the large (typically franchised) chain stores. Most are not specialists afforded a safe market space due to their unique positioning. Quite often they are generalists, operating on an entirely different scale from the large chain stores, and therefore experiencing a different environment. Their on-going survival is a testament to their adaptive abilities; to deny this would be to ignore the many factors that have changed in their individual operational environments over time. What is of critical importance is that we do not mistakenly over-focus on assumed general progress within an industry at the expense of actual specific focus being made by individual firms (Sahlins and Service, 1973). Yes, observable evolutionary trends do emerge in specific industries, but they frequently do so as the result of ecologically and behaviourally determined factors that occur at the level of the firm. Thus, firms can be viewed as relatively plastic in their abilities to behave differently to other similar firms that also acquire and use similar resources. That is, firms can be expected to demonstrate behaviours aligned to their own local ecology if we view them from a more fine-grained perspective than is common in the OE approach. 
The nature of this approach will form the focus of the discussion in Chapter 4.

We step around the problematic theory of structural inertia by expanding our concern from change occurring in the core features of any firm, to placing more concern on shifts in actual behaviour. So, regardless of what features changed or remained the same, it is the actual adaptive behaviour that is crucial. While OE is clearly an approach that has tended to focus on larger firms, FA seeks to be applicable to all types of firms, even those without complex structures, subunits, interlocking directorates and/or joint ventures (see Hannan and Freeman, 1989). It seeks to understand how firms interact with their unique operational environments in specific ways, reliant upon their sensory abilities. It is through the identification of differences in sensory abilities that FA avoids the firm equivalent of the cryptic species problem in understanding species and their diversity (see Paterson, 1993) found in the OE approach (see Freeman and Hannan, 1983), where multiple types of firms are grouped into one category despite observable differences in their environmental interactions.

In summary, OE is an approach based on specific assumptions that create much inflexibility in how we view the adaptive abilities of the firm. The forthcoming chapters will illustrate how FA frees us from such restriction through providing an introduction to the process of environmental matching (Walter and Hengeveld, 2014) through which local firms match local environs through time. To enable such analysis, we must also be mindful and able to explain the nature of environmental modification occurring between any given firm and its unique operational environment. For it is here that local selection events can be seen and understood. The subsequent outcome for all surviving firms is a fit that arises from the process of environmental matching. With Martinez and Aldrich (2012) placing great importance on understanding the nature of such a fit, FA allows consideration of its underlying processes and causes to occur at much closer range. While they correctly note the importance of consequences over intentions, FA does not need to assume that the consequences of individual intention will ultimately cascade upwards to affect populations and communities. FA remains focused on local selection events and this is the focus of the next section.

\section{Firm Modification of Operational Environments}

From an FA perspective, all individual firms are capable of changing important aspects of their operational environment. That is not to say that the intentions of the entrepreneur or manager to alter aspects of their operational environment will underwrite their continual survival. All that is being stated is that at least certain aspects of any given firm's operational environment are 
open to manipulation in some form or another. A multitude of factors, local and/or otherwise will ultimately combine to determine the degree of fit between any firm and its operational environment.

What matters is that FA does not place conditions on firm size regarding who is big or strong enough to effect such manipulation. Operating at lower ecological scales enables FA to observe environmental complexity at a level where first-hand observations are more concrete. Rather than assuming that firms belong to populations and/or communities that are subject to a relatively homogeneous selection landscape, FA seeks to understand environmental heterogeneity and how firms respond to that. The assertion that individual firms have limited resources and therefore cannot affect the environment, assumed to relate to an entire population within a common competitive environment (Martinez and Aldrich, 2012), is predicated upon the presence of an actual population of firms. As will be discussed in the following chapter, this assertion is inconsistent with the foundational principles of autecology. For now, let's consider the idea that firms can alter aspects of their environment.

From the FA perspective, the nature of interaction between firm and its operational environment represents a constant process of interpenetration between firm and environment. Such interpenetration can be viewed as the process of acquiring resources (e.g. inputs and revenue) and providing resources (e.g. products and services) to other stakeholders in its operational environment. In contrast to the prevailing logic of OE (see Hannan and Carroll, 1992), FA assumes that while individual firms are subject to environmental selection forces, those very firms are capable of also altering such selection processes through modifying aspects of their own operational environments.

Strangely, little research has explicitly examined such a process of modification (although see Jones, 2009 and Luksha, 2008), despite there being no shortage of confidence that firms do modify their environments (see March, 1994; Winter, 1990; Scott, 1987; Popper, 1972; Rumelt, 1979; Winter, 1964). However, most recent work in this area is from a coevolutionary perspective, either attributing such modification to collective behaviour, or large corporations, not small individual firms (see Child, Tse and Rodrigues, 2013).

FA is assumed not to be naturally related to the various co-evolutionary approaches operationalized in organizational studies research (e.g. Baum and Singh, 1994, Murmann, 2003; Child, Tse and Rodrigues, 2013; Abatecola, 2014; Breslin, 2014; Geels, 2014). It sees firms as often isolated from population density-dependent (competitive) factors, and quite likely to be impacted by a broader range of environmental variables, such as unique local events and/or processes. There is however room in an autecological approach 
to accommodate aspects of co-evolution, of the symmetrical kind described by Child, Tse and Rodrigues (2013), but not so asymmetrical co-evolution that essentially denies firms of all sizes the ability to significantly shape their environments. Herein lies a major difference between the FA and the more traditional OE approach. FA is focused upon individual firms and their unique operational environments. Thus, the average firm can be expected to shape many factors in its operational environment, despite not being expected to be able to modify its external (or macro) environment. The works of Child and others link together macro, meso and micro environments in such a manner that the process through which each individual firm scales its actual operational environment, is lost in the shadows of the several layers of relatively homogenous environments that are home to various populations and communities of firms.

Drawing upon the work Odling-Smee, Laland and Feldman (2003: 41) and Lewontin (1983), Jones (2009) and Luksha (2008) positioned the investigation of adaptive change relative to the on-going reciprocal interaction between the firm, the firm's behaviour and its environment. Rather than merely being on the receiving end of competitive selection, as per the OE approach, firms both modify and are adapted as a consequence of interaction with their environment. Such thinking remains consistent with the seminal arguments of Darwin's (1881) that arose from his observation that worms not only change the soil they inhabit, but also ensure a process of ecological (as well as genetic) inheritance that consequently benefits the future survival of the environment modifying worms as well as their eventual off-spring. Thus, FA in highlighting the process of environmental modification extends a focus to specific generative mechanisms through which empirical explanations of how firms might alter their environments may be crafted. The FA researcher seeks to understand how individual firms modify the feature-factor relationship between firm and operational environment. What is sought is evidence of firms changing one or more of the factors of its operational environment, "either by physically perturbing factors at its current location in time and space, or by relocating to a different space-time address, thereby exposing itself to different factors'.

From the standard evolutionary perspective, populations of firms transmit information (routines, cultures and organizational structures) from one generation to the next, under the direction of natural selection. However, enfolding the process of environmental modification into the FA approach enables direct consideration of how individual firms may modify their operational environments. From this approach, each firm (and/or those very similar) may inherit both information and a legacy of modified selection pressures (i.e. ecological inheritance) from incumbent firms. Problems encountered may not require the deliberate attempts to alter organizational 
routines. Rather, altering aspects of the operational environment may sufficiently lessen or remove the problem.

To recap, there have always existed differing views within the current literature as to whether or not individual firms are capable of altering their environments (Winter, 1964; Aldrich, 1979; Rumelt, 1979; McKelvey, 1982; Scott, 1987). Such differences of opinion are not assisted by the paucity of empirical studies addressing this fundamental issue. Introducing the idea of environmental modification, as explained above and addressed more fully in Chapter 4, offers a new window through which to consider how and under what conditions firms may alter their operational environments, and potentially those of other firms. Most importantly, we can lessen our concern of causal ambiguity (Martinez and Aldrich, 2012) whereby firms are assumed unable to determine the basis for successful performance in a given industry. Focusing upon the interaction between firm and operational environment brings the researcher face-to-face with the specific types of selection impacting upon any individual firm.

Taken together, these three issues (accounting for ecological interactions, the ability of firms to change their mode of operation and the ability of firms to modify aspects of their operational environment) represent an alternate ecological approach to the study of firm. From an FA perspective, the past development of these three issues in OE is highly problematic. The following section considers how the primary assumptions of FA, as described above, relate to the primary assumptions of other popular and related theories of the firm. The aim is to enable you to understand how FA might be used in conjunction with other common approaches. Further, to highlight why FA is either difficult to use and/or inappropriate to use with existing ecological approaches due to conflicting underlying assumptions.

\section{RELATING FA TO OTHER THEORIES OF THE FIRM}

Theories of the firm typically have two components in common: they focus on firms, and in one way or another, the environments they are held to operate in. Whether these firms are aggregated together or viewed individually, each approach is underpinned by important assumptions that provide a logic to each approach. It has been argued above that the logic upon which OE has developed is often misunderstood. As a result, OE is often interpreted too broadly as being the only way to view firms ecologically. While there have been attempts to genuinely integrate OE with the strategic management literature (Durand, 2006), doing so tends to rely on bending the original assumptions that informed the initial development of OE. Conversely, FA is argued to naturally achieve integration with several 
other theories of the firm. Let us first consider those other theories where there would appear to be opportunities for integration, starting with the best fit.

\section{Firm-level Theories}

The resource dependence theory of Pfeffer and Salancik (1978: 12) provides many similarities to FA, as described above. The unit of analysis is the same, that being the firm and its environment. There is a far greater acceptance of strategic choice (Child, 1972) than permitted in OE, simply because many firms are in reality observed to overcome the constraints they encounter. However, although there is a tight focus on the firm and its environment, this is where there are important differences also. Resource dependence theory views the environment initially as 'every event in the world which has any effect on the activities or outcomes of' firms. However, firms are not expected to understand all aspects of this environment as they are either buffered from them or ignorant of them. In this sense the environment is largely something to be known, something that can be negotiated through changing exchange relationships (Poole and Van de Ven, 2004). As organizations try to alter aspects of their environment to overcome constraints, they are likely to become subject to different constraints, and will ultimately evolve through a process of constraint avoidance. Those firms that survive are assumed to hold more power due to their interdependence and location in social space relative to other related firms. Thus all firms are not equal in terms of the abilities to alter aspects of their environment. This is an important difference with FA, given the assumption in FA that all firms can potentially alter aspects of their operational environment to adapt through time. It is through this issue where the greatest difference is, that of how the environment of each individual firm is defined. Whereas resource dependence theory sees firms located within inter-firm relationships, power constellations and other power relations, FA does not make these initial assumptions. Due to its narrower environmental focus, FA importantly grants firms greater abilities to alter aspects of their environments.

The behavioural theory of the firm (Cyert and March, 1963) places great emphasis upon organizational learning, or the ability to solve problems present within the environment, very consistent with FA. However, as originally formulated, firms are expected to negotiate their external environment through sharing in the learning of other related firms, adopting best practice to better adapt to a relatively common external environment. The environment is also assumed to produce external shocks that are uncontrollable. In this respect, the behavioural theory of the firm places far less concern on the micro-environment of the individual firm and more 
concern on interaction within the broader external environment and thus, organizational learning is seen to occur in a deeper industry context.

In a similar way, the strategic choice approach of Child (1972) also views the environment as highly complex, emerging from product and factor markets, technology, politics and socio-cultural factors. Again, these factors are seen to exist independently of any individual firm, but can be overcome through the agency that exists within firms. While this approach is interested (like FA) in the permeation between firms and their environments, there is an inevitable default to sociological ideas whereby power relations ultimately are seen to mediate interaction between the firm and its environment.

\section{Other Theories of the Firm}

Most other prominent theories either focus below the level of the firm, or above, in terms of the unit of analysis. The OE approach has been discussed above, and so will not be discussed any further at this time. Institutional theory (Meyer and Rowan, 1977; DiMaggio and Powell, 1983) sees homogeneity where FA sees heterogeneity. It also views the environment from an institutional perspective and assumes the presence of isomorphic processes that produce homogeneous firm types. Thus, firms are not seen to typically change their environment, but rather, to be changed by it, in ways that provide them with the legitimacy to survive.

Evolutionary economics (Nelson and Winter, 1982) provides an interesting approach within which a firm's routines act as mechanisms that guide local searches that ultimately produce incremental improvements in its routines. Here there is clearly a similarity with FA, which also assumes that the stability of firm routines provides a conduit for firm adaptation to occur. FA enrols the process of autopoiesis (Rose, 1997) to consider how an individual firm may be and become through precise delineation of firm boundaries (see Radosavljevic, 2008) and environment interaction. However, the conceptualization of the business environment in evolutionary economics is far broader than FA where firm adaptation is also seen to be possible without any specific change to firm routines.

Finally, the resource-based view of the firm (Penrose, 1959; Barney, 1991) is similar to the extent that it sees each individual firm as being potentially unique, due to resource heterogeneity. However, FA does not place great emphasis on the idea of a competitive advantage being obtained and/or lost due to environmental turbulence. Firms that survive, from an FA perspective, are successful regardless of their comparative resource strengths/weaknesses due to their ability to match their interacting elements with the nature of the operational environment experience and shape. 
In summary, the FA approach does not claim to displace any of the approaches discussed above. It merely seeks to establish the importance of a different set of questions. As noted previously (Alvarez, 2003: 260), each current theory of the firm has been 'developed to address a particular set of characteristics and behaviours of interest'. FA places unique emphasis upon the ability of individual firms to alter the unique operating environment they interact with. Firms can be observed doing so due to the fine-grained analysis common to autecological studies (Walter and Hengeveld, 2014). Rather than assuming that firms directly experience what is commonly called an external environment, the actual manner in which any firm scales its environment is first considered. This produces the discovery of the firm's operational environment, or, all environmental phenomena observed to have operational relations with any firm. Once we are operating at this level of analysis we are able to witness first-hand the likely process of environmental modification. From this field of view, new observations, research questions and knowledge are possible to the researcher of firms.

\section{THE PROMISE OF ANOTHER THEORY OF THE FIRM}

This chapter has introduced an alternative ecological theory of the firm and its environment. It has been claimed that this alternative approach differs from the traditional OE approach in how it accounts for the interactions between firms and the environments they experience. Further, unlike OE, the FA approach accepts the ability of firms to change their mode of operations to better match the requirements of their operational environment. Finally, and most importantly, the FA approach promotes the ability of firms to modify aspects of their operational environment in ways that alter the nature of selection they experience. These three specific differences do more than merely distinguish FA from the traditional OE approach; they also provide an exciting pathway to connect FA to many common assumptions held within other theories of the firm.

For example, FA as proposed fully embraces all aspects of the organizational learning literature. In doing so it focuses upon the specific learning processes of the firm doing the learning. Rather than requiring the process of learning to be illustrated across time in longitudinal studies or at multi-levels of analysis, we can be content with observing the learning that most influences the feature-factor relationship between firm and operational environment (see Poole and Van de Ven, 2004). The nature of generalization possible through FA lends itself to such simple, yet potentially broad observations. FA expects to find complex patterns of learning across different types of firms. It uses heuristic generalizations to guide such investigation of 
firm-environment interaction. Thus, there are no assumed laws related to firm learning that firms would be expected universally to comply to.

FA makes it possible to connect the field of organizational studies to the current renaissance of autecological thinking (see Walter and Hegeveld, 2014). It also enables an explicit focus on adaptive mechanisms, sensory abilities, and the process through which firms modify their interactive elements (see Jones, 2005) to better match the requirements of their operational environment. Interestingly, FA draws upon Rose's (1997) idea of a lifeline to also explicitly consider the nature of environmental matching occurring across the different phases of a firm's lifeline. The operational environment is therefore directed, timed, ordered and spaced by and across the lifeline of a given firm.

The next chapter consider the question, what is a firm? It will be argued that neither routines nor firms can be seen as isolated from their own operational environments, as they constantly interpenetrate each other. It will be argued that every firm has, in its organization, a range of sustenance activities, these being organized regularly and enduring activities aimed at supporting firm survival (see Gibbs and Martin, 1959). So while various aspects of the firm must change to facilitate continual adaptation, order must remain within the firm's sustenance activities to allow the firm to both be and become. 
Colin Jones and Gimme Walter - 9781784711016 Downloaded from PubFactory at 04/26/2023 12:34:57PM via free access 